\title{
Editorial: The Lessons of 1989?
}

In the former Eastern bloc people have been celebrating the twentieth anniversary of the fall of the Berlin wall. They have also been asking themselves what lessons might have been learned in the two decades since the dramatic events of late 1989.

In the context, and remembering not just Hegel's stress on the philosophical significance of world-historical events, but also his words about the owl of Minerva flying only at dusk, it is surely appropriate twenty years on to ask what philosophy in the West has learned as a result of 1989.

It cannot be said that on the face of it, apart from a possible reluctance to use the term 'socialism', the substance of Anglo-American political philosophy has been greatly affected. The debates seem much the same as they have been since John Rawls changed the orientation of the subject half a century ago. Maybe we in the West have little to learn from the experience of the USSR and its empire, and simply need to continue refining our efforts to reconcile liberty and equality, redistribution and freedom, community and choice.

But maybe, twenty years on, if the reception accorded to the late G. A. Cohen's Why Not Socialism? is a guide, the very term 'socialism' is about to re-enter the vocabulary of mainstream political philosophy. In his short book, published by the Princeton University Press in 2009, Cohen posed the question as to why the behaviour of friends on a camping trip - which he sees as essentially socialistic could not be replicated in society at large.

Cohen did not pause to ask where the friends might have acquired the resources to go camping, but engaged in a broad brush comparison of market activity with that of friendly campers. Every market is a system of predation. Greed and fear are what bring markets to prominence. Moral shabbiness is the mark of market motivation. Markets (even social markets) are intrinsically repugnant. By contrast markets, with socialism, as with our campers, the focus is on community and caring and equality of opportunity.

Put in these terms the contest is over before it begins, though at this level of analysis one could just as well assert that socialism is all about resentment, envy, dependency and the will to power of the petty (and not so petty) would-be bureaucrat and commissar, whereas markets foster responsibility, freedom, hard work, family values, creativity and initiative. 


\section{Editorial}

Cohen's rhetoric is eerily reminiscent of that which paved the way for the revolutions of the twentieth century. But perhaps most significant remark in his short text is that 'we don't now know how to give collective ownership and equality the real meaning that it had in the camping trip story but which it didn't have in the Soviet Union and similarly ordered states.' Twenty (or is it really ninety?) years on, it looks as if, far from soaring into the dusk, the owl of 1989 is still in its egg. 